Brief note

\title{
MEASUREMENTS OF TEMPERATURE OF CNC MACHINE TOOL BALL SCREW UTILISING IR METHOD
}

\author{
J. ZAPŁATA \\ West Pomeranian University of Technology in Szczecin \\ Faculty of Mechanical Engineering \\ al. Piastów 19, 70-310 Szczecin, POLAND \\ E-mail: jacek.zaplata@zut.edu.pl
}

\begin{abstract}
In numerous papers it is proposed to use IR measurements of feed axis ball screw temperature distribution in order to compensate $\mathrm{CNC}$ machine tool thermal errors. The paper aims to validate reliability of the IR measurements in application to the feed axes ball screws. The identification of key factors influencing the accuracy of the IR measurements of ball screw temperature distribution has been conducted. A test-bench utilizing a ball screw assembly with built-in temperature sensors was introduced and the experimental data are presented along with conclusions.
\end{abstract}

Key words: thermography, ball screws, $\mathrm{CNC}$ machine tools, thermal error.

\section{Introduction}

Numerous papers concerning the subject of compensation of CNC machine thermal errors [1-3] present thermograms of ball screw driven feed axes as a validation of their thesis. Some authors even propose to use the IR measurements of temperature distribution of feed axis ball screws in order to compensate machine tool thermal errors [4-6].

The paper [1] presents thermal deformation modelling of a dual-drive jig boring machine. The machine tool was equipped with two ball screws driving the $X$ axis. An IR camera was used to measure the temperature field of the machine tool surface and a contact method for point temperature measurements was employed. The contact temperature measurements were conducted in order to evaluate the emissivity coefficients of machine tool surfaces. Basing on the modelled temperature field, the thermal deformation analysis was conducted. However, no thermal contact sensors were placed on the ball screws leading to discrepancy between the modelled and the measured temperature field.

An IR camera was used to measure the temperature of a CNC axis ball screw [4]. By means of image processing 131 measuring points along the axis of the ball screw were selected. Since the ball screw was temporarily obstructed by the moving nut, the temperature of the complete image was achieved by summation of multiple images. Using the measured temperature field thermal deformations were computed. Verification of the modeled data by means of a laser interferometer measurement showed the proposed method maximal error slightly exceeded $20 \%$. It was noted that the inaccuracy occurred due to the reflections of ambient radiation and the inhomogeneity of the emissivity of the ball screw.

The article [5] also presents IR measurements performed in order to model thermal deformations of a ball screw. The authors remarked that the inhomogeneity of the emissivity coefficient of the ball screw surfaces is apparently caused by multiple reflections inside the concave surface of the ball screw thread.

This paper aims to validate the reliability of the IR measurements in application to the feed axes ball screws thermal error compensation. The key factors influencing the accuracy of the IR measurements of ball screw temperature distribution have been identified. 


\section{Influence of material emissivity coefficient on IR measurement accuracy}

According to the fundamental equation of radiometry, the radiance $\mathrm{L}_{\text {det }}$ detected by an IR camera, when observing a surface of temperature $\mathrm{T}_{\text {surf }}$, is equal to [7]

$$
L_{D E T}=\tau \cdot \varepsilon \cdot L_{B B}\left(T_{S U R F}\right)+\tau \cdot(1-\varepsilon) \cdot L_{B B}\left(T_{A M B}\right)+(1-\tau) \cdot L_{B B}\left(T_{A T M}\right) .
$$

In the case of machine tools observation, the IR camera is in proximity of the ball screws, therefore the value of the transmission coefficient is close to $\tau \approx 1$. Equation (2.1) shows that in order to conduct proper IR temperature measurements the emissivity coefficient value of an observed surface $(\varepsilon)$ has to be specified. This fact is often neglected and the $\varepsilon$ value is assumed a priori.

Such a practice may result in major inaccuracy, because the $\varepsilon$ value is diverse, and usually difficult to estimate precisely. It depends on the material type, surface roughness and shape, observation angle, surface temperature, and, regarding non-gray bodies, spectral sensitivity of the IR camera. Typically, for nonoxidized metallic surfaces the $\varepsilon$-value is low, whereas for dielectric or paint-coated surfaces it is rather high, e.g., for rolled steel at $25^{\circ} \mathrm{C} \varepsilon=0.06$, for polished gray cast iron at $200^{\circ} \mathrm{C} \varepsilon=0.21$, for oil paint at $0^{\circ} \mathrm{C} \varepsilon$ $=0.885$, for black rough rubber at $24^{\circ} \mathrm{C} \varepsilon=0.95$ [8]. However, using the tabulated values is often misleading. The most reliable data are achieved by direct measurement. Two methods are used commonly for in situ measurements [9, 10]:

- coating the surface of unknown $\varepsilon$-value with tape of known $\varepsilon$-value,

- an additional measurement of the observed object temperature using a contact method.

Steel ball screw surfaces are characterized by a small value of the thermal emissivity coefficient, since tribological requirements require its low roughness, thus, it leads to difficulties in accurate thermographic measurement. In order to enlarge the $\varepsilon$-value tape or paint coatings are utilized $[1,9,10]$. However, in the case of a moving screw-nut assembly this solution is hazardous since the cleanness of ball screw tread surfaces is of major importance. Therefore, the measurements are usually performed directly on ball screw surfaces $[4,5]$.

The influence of $\varepsilon$-value error on the error of temperature measurement can be estimated using Eqs $(2.2) \div(2.5)[9,10]$, if the IR camera algorithm is known. Usually, during the calibration process of an IR camera the relation between a black body calibration source temperature $\mathrm{T}_{\mathrm{BB}}$ and recorded camera signal $\mathrm{S}$ is established in the form

$$
S\left(T_{B B}\right)=\frac{C_{1}}{\exp \left(\frac{C_{2}}{T_{B B}}\right)-C_{3}}
$$

where: $C_{1}, C_{2}, C_{3}$ are calculated using best fit procedure. Factors found during the calibration process are only valid for the tested set including the camera and lens, thus exchanging lens requires changing camera calibration settings.

The relation between the camera signal and radiance impinging on the camera detector is given by

$$
S=C \cdot \int_{\lambda_{l}}^{\lambda_{2}} R(\lambda) \cdot L_{D E T} d \lambda
$$

where: For a black body Eq.(2.3) is equal to

$$
S\left(T_{B B}\right)=C \cdot \int_{\lambda_{1}}^{\lambda_{2}} R(\lambda) \cdot L_{B B} d \lambda \text {. }
$$


Taking into consideration that $\tau=1$, Eq.(2.1) can be transformed to

$$
L_{B B}\left(T_{S U R F}\right)=\frac{L_{D E T}-(1-\varepsilon) \cdot L_{B B}\left(T_{A M B}\right)}{\varepsilon} .
$$

The above equation set (2.2), (2.4), (2.5) gives a relation between the surface temperature $T_{S U R F}$, the surface emissivity coefficient $\varepsilon$ and the camera output signal $S$. On that basis, the influence of the emissivity uncertainty on the measured temperature uncertainty could be derived. Unfortunately, $C, C_{1}, C_{2}, C_{3}$ and function $R(\lambda)$ are rarely unveiled by IR camera manufacturers. W. Minkina managed to acquire the factors for research purposes, and presented relations between the relative temperature error $\Delta T_{S U R F} / T_{S U R F}$ and relative emissivity coefficient error $\Delta \varepsilon / \varepsilon$ in a graphical form [10].

Table 1. The value of the temperature error $\Delta T_{S U R F}$ of an IR measurement as a function of the emissivity error $\Delta \varepsilon$ and temperature of the observed surface $T_{S U R F}$. The true value of emissivity $\varepsilon=0.4$. Ambient temperature value $T_{A M B}=20^{\circ} \mathrm{C}$. Based on [10].

\begin{tabular}{|c|c|c|c|c|}
\hline & & \multicolumn{3}{|c|}{$\Delta \varepsilon$} \\
\hline & & 0.04 & 0.08 & 0.12 \\
\hline \multirow{2}{*}{$\stackrel{\text { 岕 }}{\stackrel{\vec{w}}{⺊}}$} & $30^{\circ} \mathrm{C}$ & $1.0^{\circ} \mathrm{C}$ & $2.5^{\circ} \mathrm{C}$ & $3.9^{\circ} \mathrm{C}$ \\
\hline & $50^{\circ} \mathrm{C}$ & $2.7^{\circ} \mathrm{C}$ & $6.4^{\circ} \mathrm{C}$ & $10.0^{\circ} \mathrm{C}$ \\
\hline
\end{tabular}

Table 2. The value of the temperature error $\Delta T_{S U R F}$ of an IR measurement as a function of the emissivity value $\varepsilon$ and temperature of the observed surface $T_{S U R F}$. The value of the emissivity error $\Delta \varepsilon=0.1$ Ambient temperature value $T_{A M B}=20^{\circ} \mathrm{C}$. Based on [10].

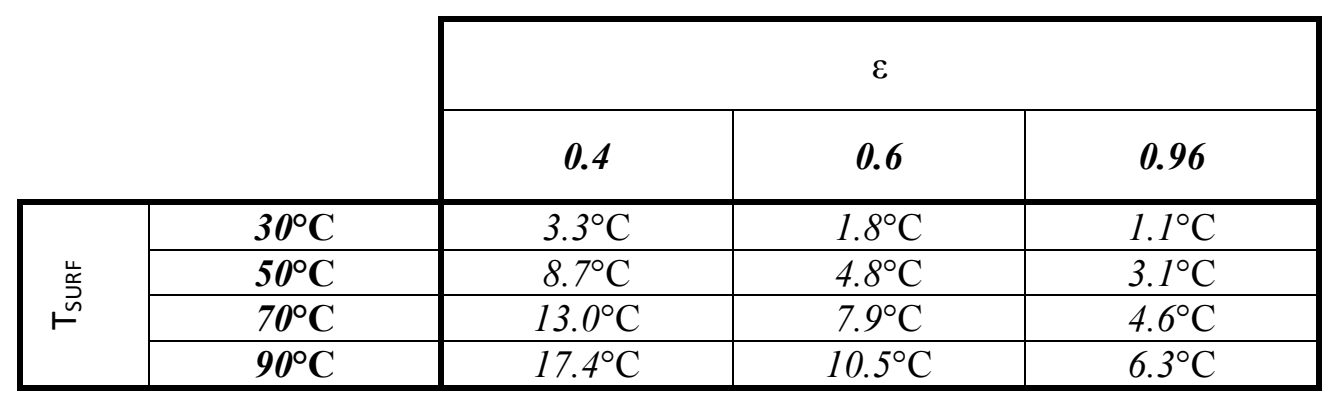

Table 1 presents the influence of the emissivity coefficient error and the observed surface temperature values on the temperature error. Table 2 presents the influence of emissivity and observed surface temperature values on the temperature error at a constant value of the emissivity error $\Delta \varepsilon=0.1$. It is shown that the temperature error increases with decreasing emissivity and increasing temperature of the observed surface.

For a ball screw the expected surface emissivity coefficient $\varepsilon$ varies in the range of $0.1 \div 0.4$. The temperature increase of the ball screw caused by the work is usually in range of $10 \div 20^{\circ} \mathrm{C}[11,12]$. Therefore, in the case of the ball screw temperature measurement using IR methods, aimed for thermal error compensation, the emissivity error influence on the temperature measurement error value is significant. Commercial software presently available dedicated for thermal analysis, enables defining local $\varepsilon$-values for user-defined areas. 


\section{Influence of observation angle and surface shape on IR measurement accuracy}

In the case of metal surfaces, barely oxidized, directional emissivity changes noticeably with increasing the observation angle, reaching its maximum around $80^{\circ}$ and decreasing to $\varepsilon \approx 0$ at grazing angles $[7,13]$. In the case of concave surfaces the apparent emissivity is enlarged by multiple reflexions. Kanayama [14] published formulas defining the value of apparent directional emissivity for V-groove opening and circular groove. However, the calculated and measured values differ up to $25 \%$. Peeters et al. [15] conducted an experiment homogeneously heating a steel and nylon tube, modelling an apparent surface temperature which was measured by an IR camera. They used SIEMENS NX FEM software and Monte Carlo ray tracing technique, achieving good conformity for the nylon tube, and less accurate results for the steel tube (due to surface inhomogeneity).

\section{Experimental verification of IR temperature measurement accuracy for a ball screw}

In order to investigate the IR measurement accuracy in application to ball screws, three different ways of measurement were compared:

- the contact temperature measurement by use of built-in temperature sensors,

- the IR temperature measurement on the surface of a highly emissive vinyl tape mounted on the surface of the ball screw at the location of contact sensors,

- the IR temperature measurement directly on the convex surface of the ball screw located near the contact sensors.

The measuring set is presented in Fig.1. IST TSic716 contact temperature sensors were mounted inside the ball screw as shown in Fig.2. The sensors have a digital interface and accuracy equal to $0.07^{\circ} \mathrm{C}$. They were connected to a digital input module of National Instrument NI9022 data acquisition set.

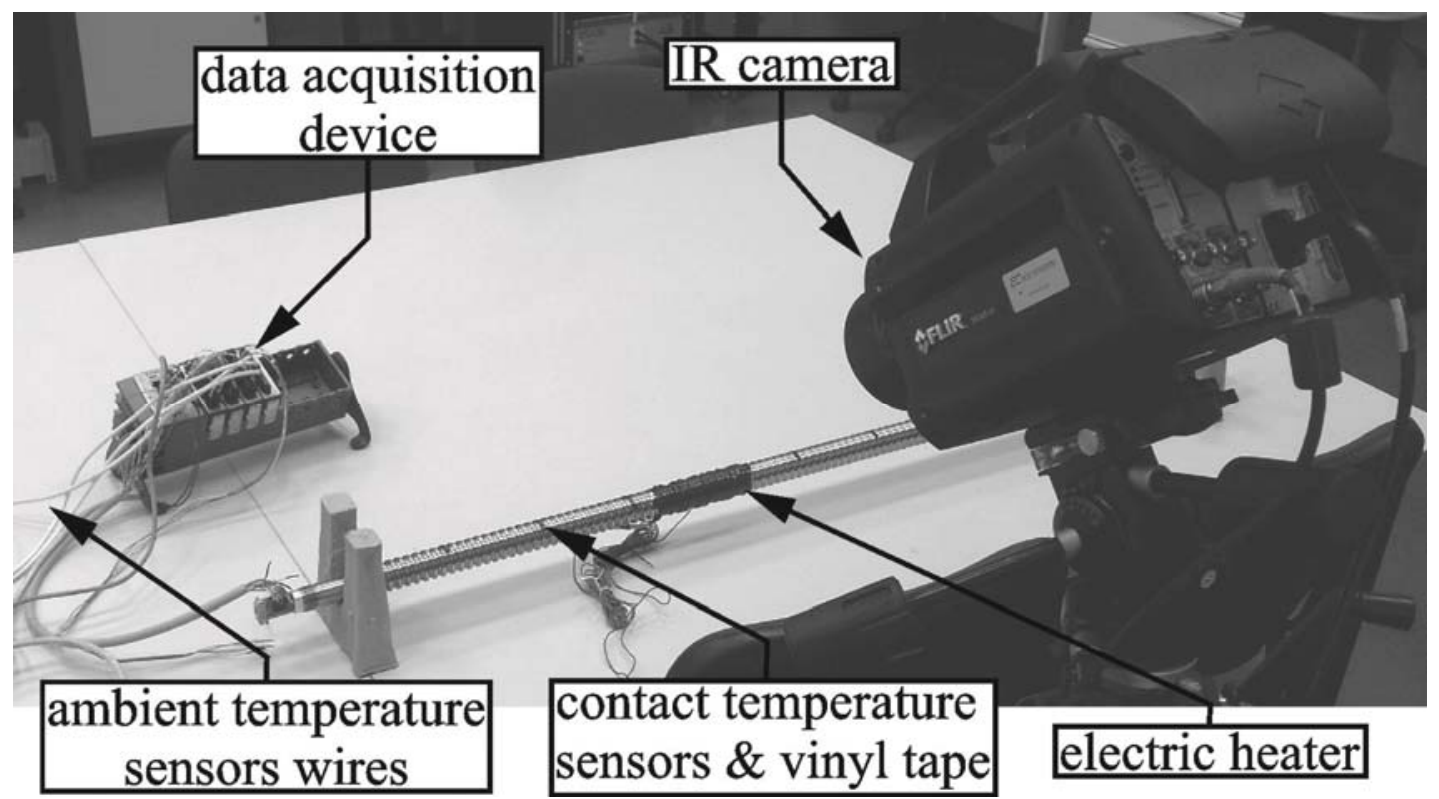

Fig.1. The measuring stand.

The measurements were conducted in an air-conditioned room at a temperature of $21.5^{\circ} \mathrm{C}$. The ambient air temperature was recorded by PT100 sensors connected to the data acquisition set. The recorded change of ambient temperature during the experiment was less than $0.1{ }^{\circ} \mathrm{C}$. The stationary ball screw was heated electrically by a coiled resistance wire. The FLIR X6540sc camera with $25 \mathrm{~mm}$ focal length lens was used for the IR measurements. The distance between the camera and the screw was equal to $2.5 \mathrm{~m}$. The 
emissivity of the vinyl tape, mounted at the location of contact temperature sensors (Fig.2), was equal to $\varepsilon_{\mathrm{VT}}$ $=0.97 \pm 0.1$. This emissivity was evaluated by means of heating the tape on a precision heating plate with a built-in temperature sensor.

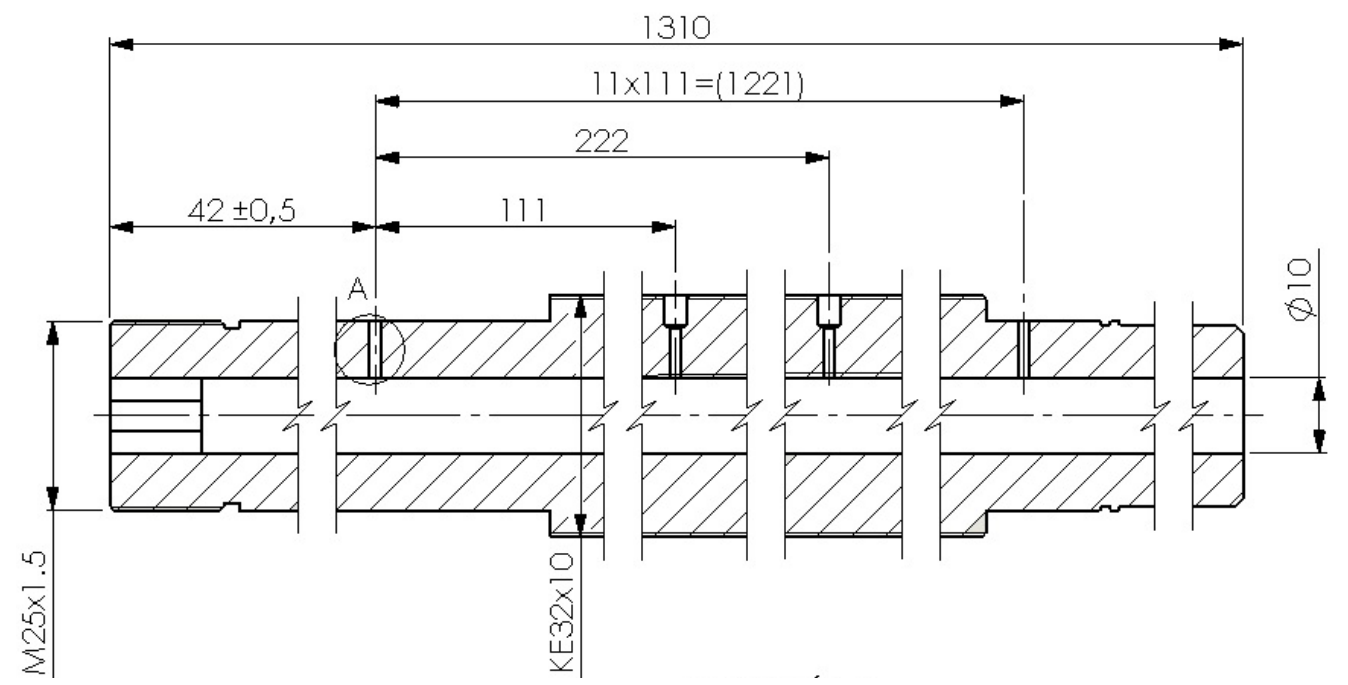

Fig.2. The cross-section of the ball screw revealing the location of contact temperature sensors.

Figures 3 and 4 present a comparison of the temperature values measured by the contact method with temperatures recorded by the IR camera. Figure 3 shows the results of IR observation at the surfaces covered by a vinyl tape. The IR camera temperature results are similar to the ones recorded by the contact sensors, as a consequence of high emissivity of the tape.
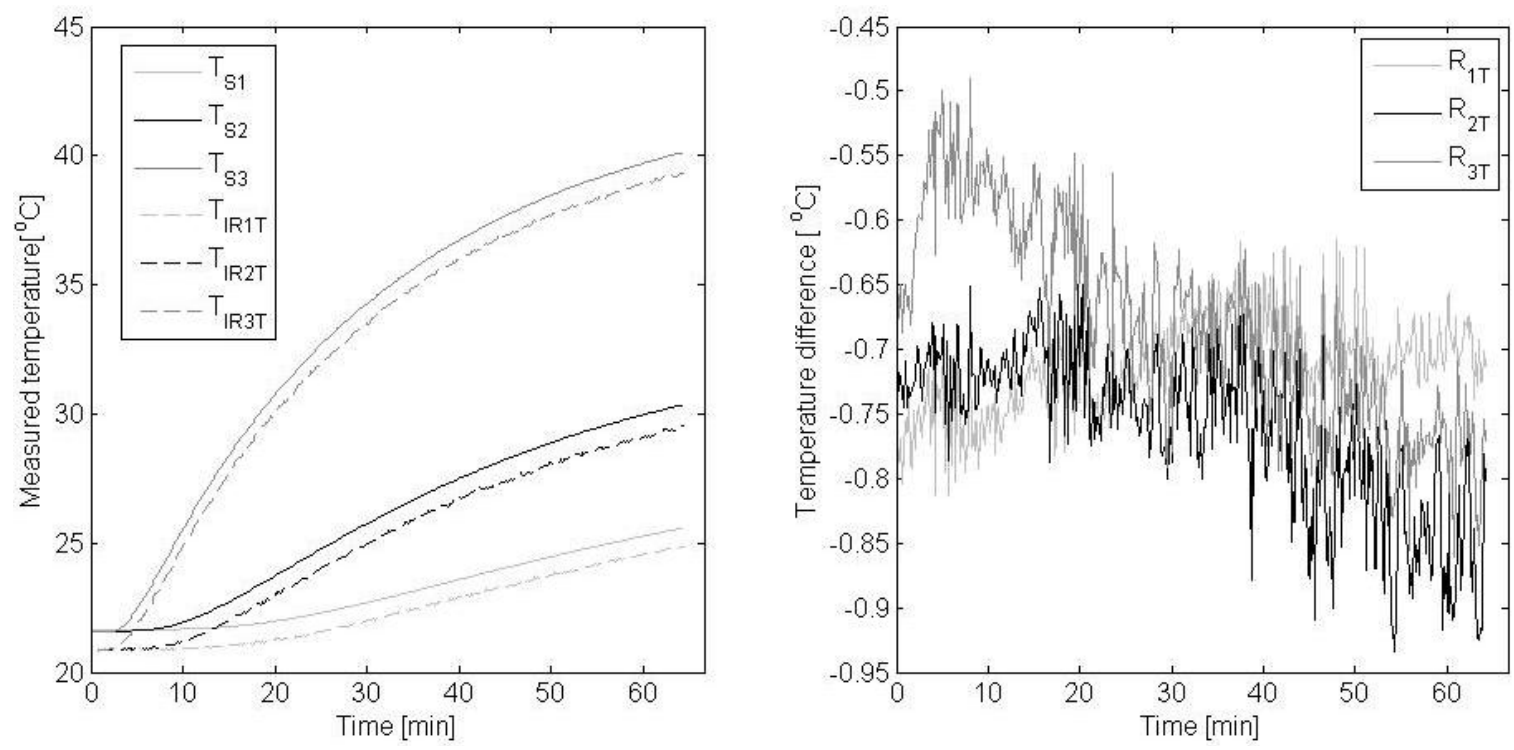

Fig.3. A comparison of temperature values measured using contact sensors and IR camera observing the surface of vinyl tape.

Figure 4 shows the results of IR observation conducted directly on convex surfaces of the ball screw. Differences between the results obtained by means of the IR and the contact method are significant, showing that the former method is insufficient for the application to the thermal error compensation. The emissivity value of the ball screw convex surface was evaluated according to the 3rd sensor readings. 

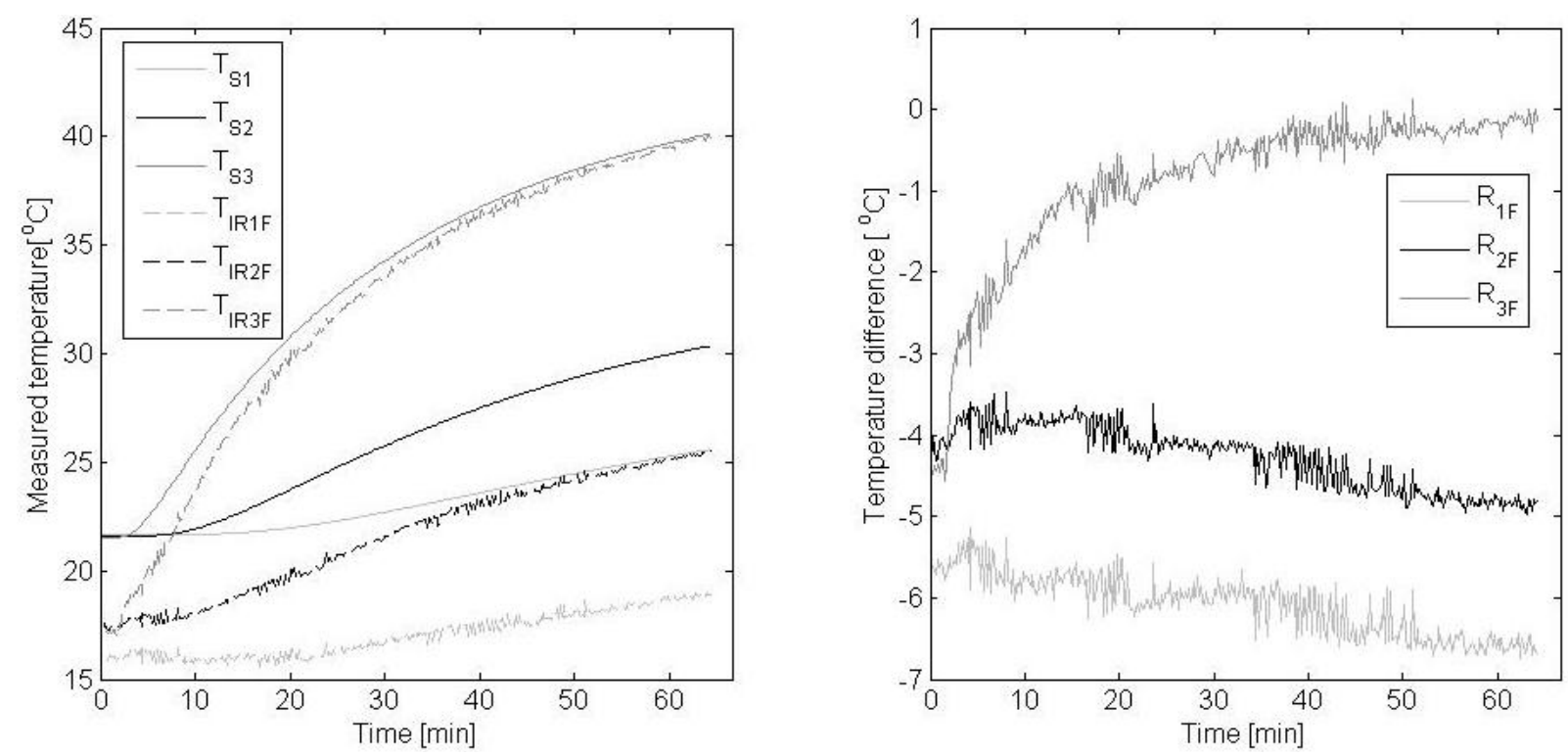

Fig.4. A comparison of temperature values measured using contact sensors and IR camera observing the non-coated surface of ball screw.

\section{Enhancing IR measurement accuracy by taking advantage of non-uniform emissivity coefficient}

The observation of the heated ball screw in IR spectrum (Figs 5, 6) shows the non-uniformity of the ball screw emissivity. Line 1 and line 2 were marked at Fig.6. The values of the recorded signal along those lines are presented at Fig.5. It can be noticed that the value of emissivity increases at the grooved surfaces (line 1) due to internal reflections and at margins of the convex surface ball screw surface due to changes of material directional emissivity (line 2).
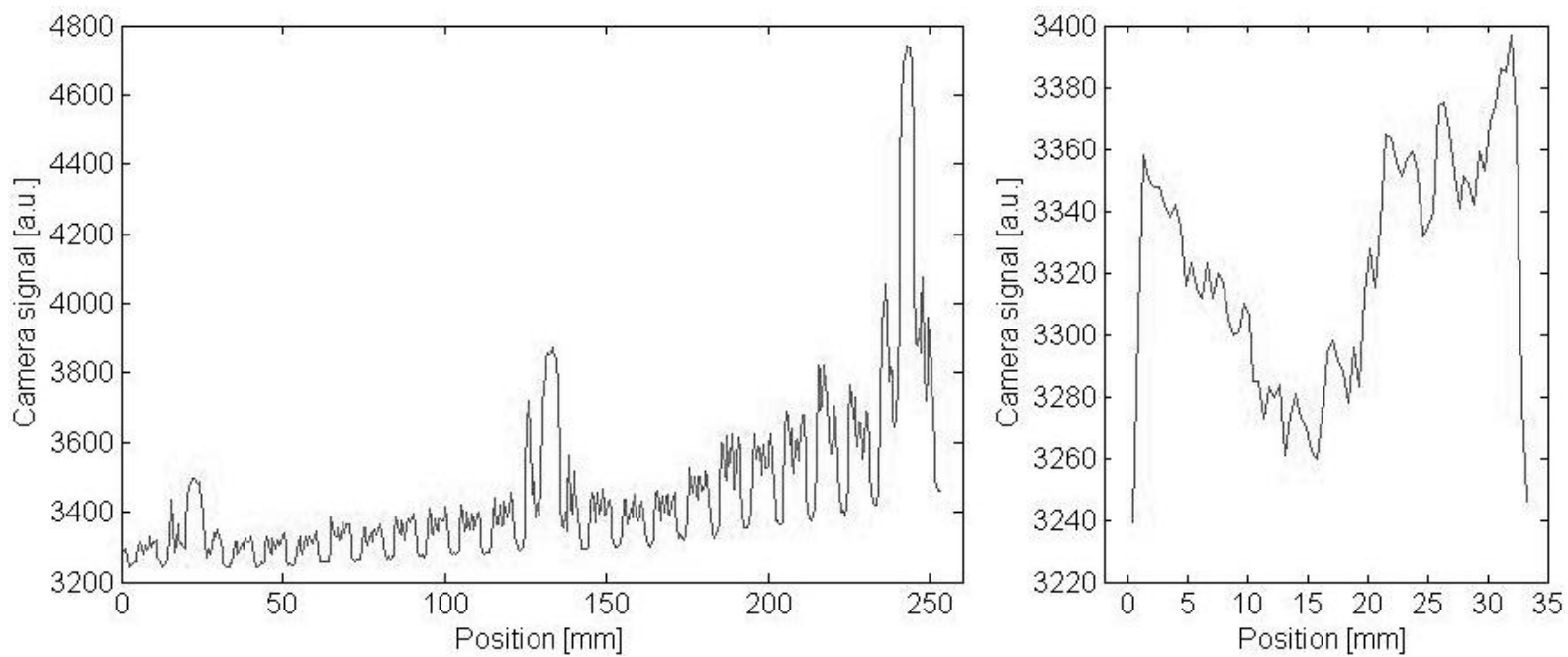

Fig.5. The IR camera signal recorded along line 1 (left side) and line 2 (right side). 


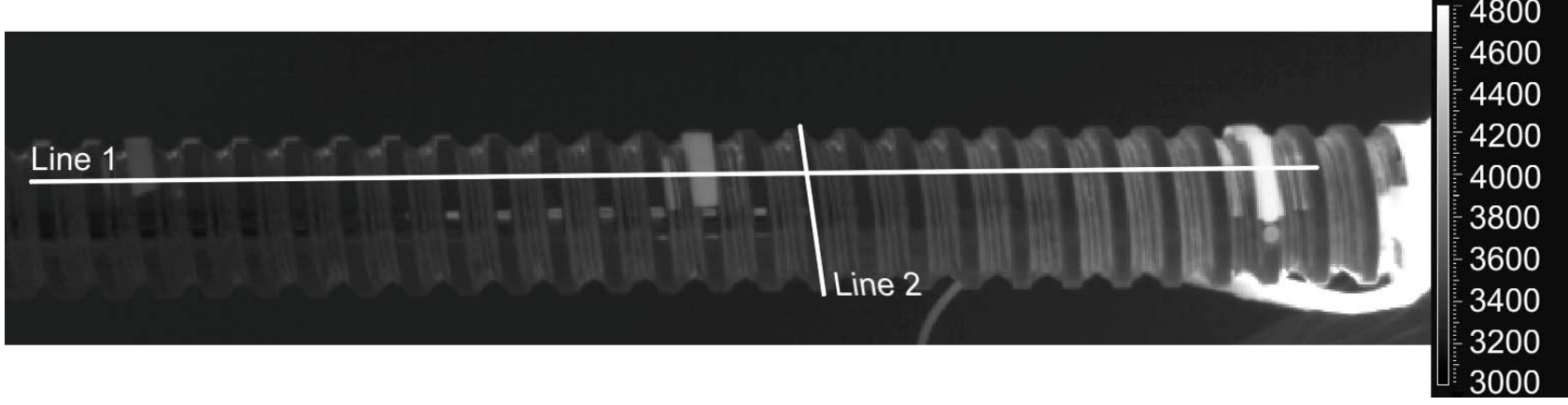

Fig.6. A thermogram of the heated ball screw, [a.u.]

The temperature measurements with use of IR method were conducted at surfaces of ball screw thread grooves. The measurement results are presented in Fig.7. This leads to an improvement of measurement accuracy in comparison to the accuracy achieved by IR measurement at the convex surface of ball screw (Fig.4).

However, the achiwed temperature measurement accuracy is still unsatisfactory for thermal error compensation. Though some adjustment of the compensation model may lead to a partial agreement of the measured and modelled thermal error, the global conformance of thermal error compensation basing on inaccurate temperature measurement may be questioned.
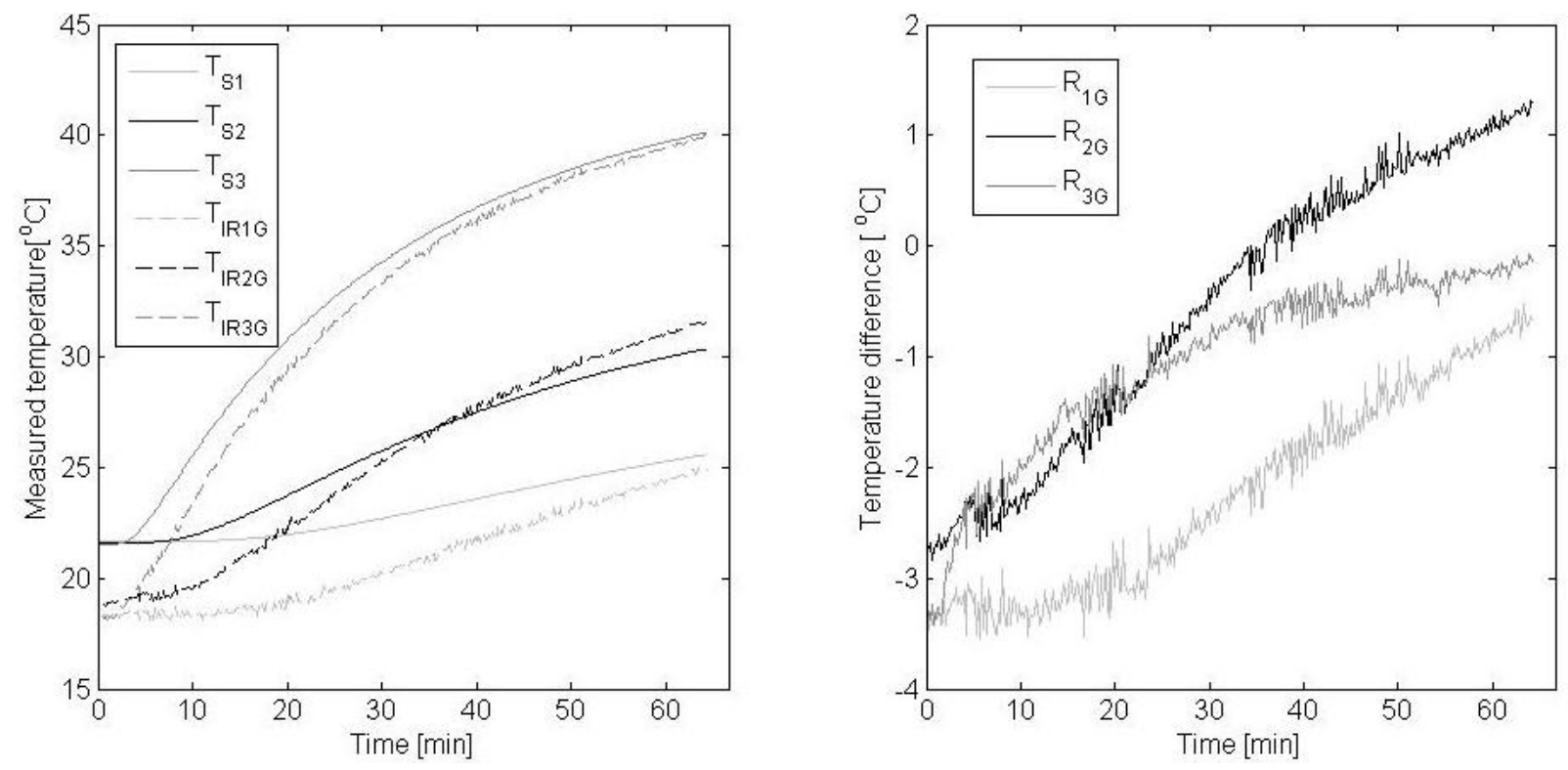

Fig.7. A comparison of the temperature values measured using contact sensors and IR camera observing ball screw grooves.

\section{Conclusions}

The article depicts the IR measurement accuracy of feed axes ball screws. It has been shown that, apart from current sluice-gate price of IR measurements, the IR measurement accuracy might also be insufficient in application for ball screw thermal error compensation. An enhancement of the IR measuring technique of ball screw temperature using the ball screw non-uniform emissivity was proposed. It allows an improvement of the measurement accuracy. 


\section{Nomenclature}

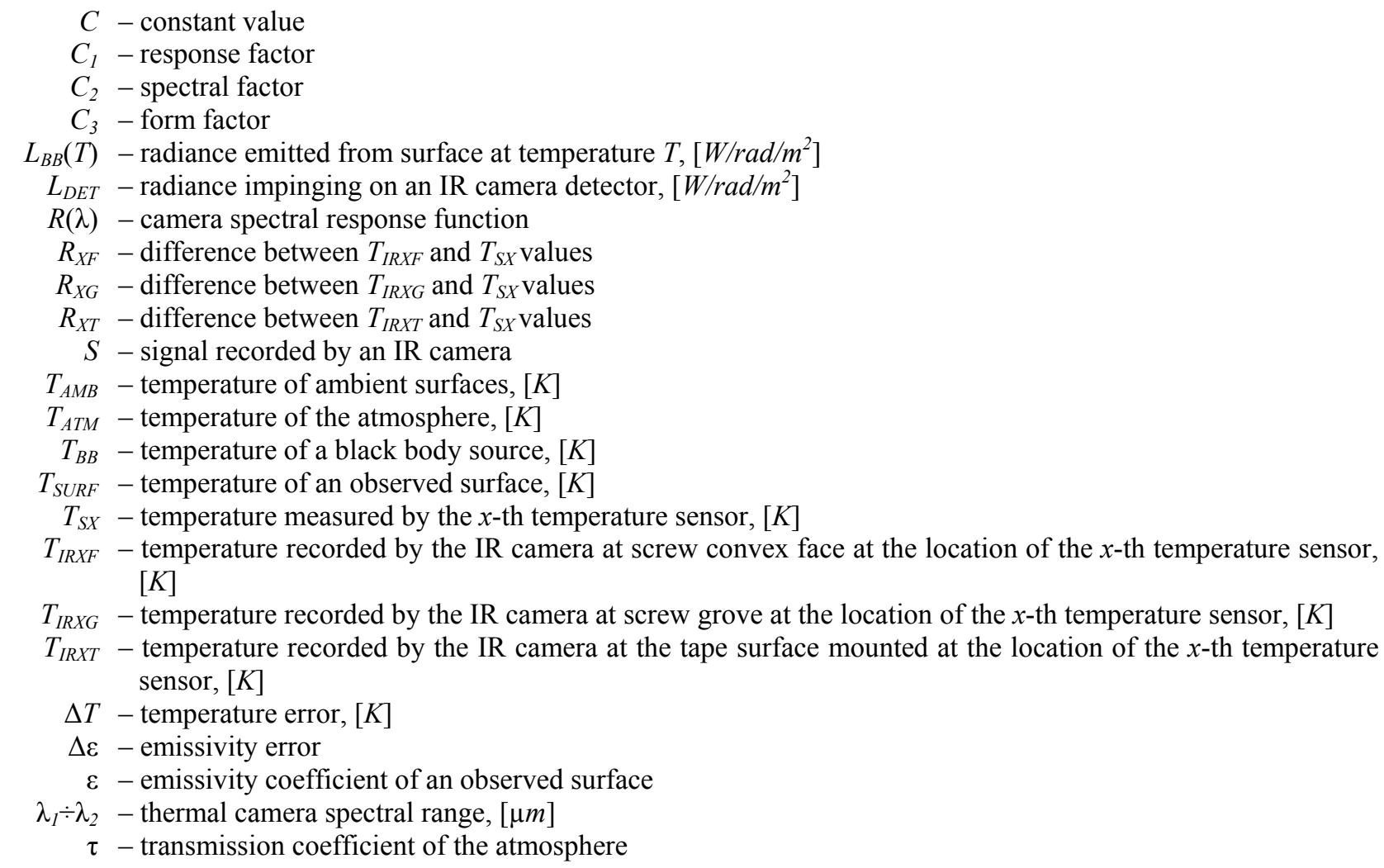

\section{References}

[1] Yang J., Mei X., Feng B., Zhao L., Ma C. and Shi H. (2015): Experiments and simulation of thermal behaviors of the dual-drive servo feed system. - Chinese Journal Of Mechanical Engineering, vol.28, pp.76-87.

[2] Jin C., Wu B. and Hu Y. (2015): Study on thermal behavior analysis of nut/shaft air cooling ball screw for highprecision feed drive. - Int. J. Adv. Manuf. Technol., vol.77, pp.1979-1992.

[3] Różański L. and Poloszyk S. (2004): Application of thermovision in machine diagnostics. Madura H. (red.) Practical thermovision measurements, pp.75-83. - Warsaw: PAK.

[4] Heisel U., Koscsak G. and Stehle T. (2006): Thermography-based investigation into thermally induced positioning errors of feed drives by example of a ball screw. - CIRP Annals - Manufacturing Technology, vol.55, pp.423-426.

[5] Horejš O., Bárta P. and Hornych J. (2007): Determination of positioning error of feed axes due to thermal expansion by infrared thermography. - ATEM'07, JSME-MMD, Sep. 12-14.

[6] Shi H., Ma C., Yang J., Zhao L., Mei X. and Gong G. (2016): Investigation into effect of thermal expansion on thermally induced error of ball screw feed drive system of precision machine tools. - Int. J. of Adv. Manuf. Technol., vol.82, pp.1693-1705.

[7] Maldague X. (1994): Infrared methodology and technology. - Amsterdam: Gordon and Breach Science Publishers.

[8] Raznjevic K. (1964): Heat transfer charts with graphs: numerical data in units of technical and international system. - Warsaw: WNT.

[9] Vollmer M. and Möllmann K.-P. (2010): Infrared thermal imaging. - Weinheim: Wiley-VCH.

[10] Minkina W. and Dudzik S. (2009): Infrared thermography: errors and uncertainties. - Witshire: John Wiley and Sons. 
[11] Pajor M. and Zapłata J. (2014): Intelligent machine tool - A thermal diagnostic system for a CNC pretensioned ball screw. - Solid State Phenomena, vol.220-221, pp.491-496.

[12] Pajor M. and Zapłata J. (2013): Supervising and compensation of thermal error of CNC feed ball screw. Diagnostics, vol.14, pp.37-42.

[13] Holman J.P (1986): Heat Transfer, sixth edition. - Singapore: McGraw-Hill Book Company.

[14] Kanayama K. (1972): Apparent directional emittances of V-groove and circular-groove rough surfaces. - Heat Transfer - Jpn. Res., vol.1, pp.41-49.

[15] Peeters J., Ribbens B., Dirckx J. and Steenackers G. (2016): Determining directional emissivity: Numerical estimation and experimental validation by using infrared thermography. - Infrared Physics and Technology, vol.77, pp.344-350.

Received: October 18, 2016

Revised: May 26, 2017 